\title{
INFLUÊNCIA DA VIBRAÇÃO DAS HASTES E DA VELOCIDADE DE DESLOCAMENTO DA COLHEDORA NO PROCESSO DE COLHEITA MECANIZADA DO CAFÉ ${ }^{1}$
}

\author{
EZEQUIEL DE OLIVEIRA ${ }^{2}$, FÁBIO M. DA SILVA ${ }^{3}$, NILSON SALVADOR ${ }^{4}$, \\ CARLOS A. P. FIGUEIREDO ${ }^{5}$
}

\begin{abstract}
RESUMO: Hoje, já existem vários estudos sobre a eficiência operacional de colheita mecanizada do café, porém pouco se sabe sobre a influência da vibração das hastes e a velocidade de deslocamento da colhedora nesse processo. Assim, este trabalho teve por objetivo avaliar a influência da vibração das hastes e da velocidade de deslocamento da colhedora no processo de colheita mecanizada do café. O trabalho foi desenvolvido na Fazenda Capetinga, sul de Minas Gerais. Para os ensaios, utilizou-se do delineamento inteiramente casualizado, com quatro repetições, em parcelas aleatórias, contendo, em média, 40 plantas em fileira. Os ensaios foram realizados com duas passadas da colhedora, definidos em função do índice de frutos verdes na planta. A primeira passada foi realizada com média de $30 \%$ de verde, e a segunda, com média de $10 \%$ de verde. Concluiu-se que, na primeira passada, o volume de café colhido, a desfolha e a eficiência de derriça foram $29,25 \%, 31,12 \%$ e $31,85 \%$, respectivamente, superiores na maior vibração. Na segunda passada, na maior velocidade operacional, o volume de café caído no chão variou $61,2 \%$ em relação à menor velocidade, e a redução no volume colhido e na eficiência de colheita variou de $14,28 \%$ da menor para a maior velocidade operacional.
\end{abstract}

PALAVRAS-CHAVE: cafeicultura, mecanização agrícola, derriça.

\section{THE INFLUENCE OF THE STICKS VIBRATION AND THE SPEED IN THE DISPLACEMENT OF THE HARVESTER MACHINE ON MECHANIZED COFFEE HARVEST PROCESS}

\begin{abstract}
Nowadays, there are many studies about the efficiency of the mechanized coffee harvest but not much is known about the influence of the sticks vibration and the speed of the harvester machine on the mechanized coffee harvest process. The goal of this paper was to evaluate this influence. The study was conducted at the Capetinga Farm, south of the state of Minas Gerais. For the experiments, it was utilized the randomized design with four repetitions in aleatory portions having, on average, 40 plants in each line. The experiments were done with two runs of the harvester considering the green coffee berries rate. The first run was done having $30 \%$ of green coffee berries and, on the second one, about $10 \%$ of green coffee berries. It was concluded that, on the first run, the volume of coffee berries harvested, the leaf loss and the seed dropping efficiencies were $29.25 \%, 31.12 \%$ and $31.85 \%$, respectively, having better results when operating with the highest vibration. On the second run, with the highest operational speed, the volume of coffee berry that fell on the ground varied $61.2 \%$ in relation to the lowest speed and the reduction on the harvested volume and in the harvest efficiency varied $14.28 \%$ from the lowest to the highest operational speed.
\end{abstract}

KEYWORDS: coffee plantation, agricultural mechanization, seed dropping.

\footnotetext{
${ }^{1}$ Extraído da dissertação de mestrado do primeiro autor. Premiado no CONBEA 2007 como melhor dissertação de mestrado na área de Máquinas e Mecanização Agrícola.

${ }^{2}$ Eng ${ }^{\circ}$ Agrícola, Mestre em Engenharia Agrícola, Universidade Federal de Lavras, Departamento de Engenharia, Caixa Postal 37, Lavras - MG, ezequielufla@yahoo.com.br

${ }^{3}$ Engo ${ }^{\circ}$ Agrícola, Prof. Adjunto, Departamento de Engenharia, UFLA, Lavras - MG.

${ }^{4}$ Eng $^{\mathrm{O}}$ Agrícola, Prof. Titular, Departamento de Engenharia, UFLA, Lavras - MG.

${ }^{5}$ Graduando em Engenharia Agrícola, UFLA, Lavras - MG.

Recebido pelo Conselho Editorial em: 31-7-2006
}

Aprovado pelo Conselho Editorial em: 15-8-2007 


\section{INTRODUÇÃO}

A colheita do café é uma operação complexa, pois se constitui de uma série de operações, tais como: arruação, derriça, varrição, recolhimento, abanação e transporte, devendo ser iniciada quando a maior parte dos frutos estiver maduro e antes que se inicie a queda dos frutos secos (IBC, 1974).

Comparativamente a outras culturas, a colheita do café é mais difícil de ser executada, em razão do formato da planta, da desuniformidade de maturação e do elevado teor de água dos frutos, o que prejudica a mecanização das operações (FILGUERAS, 2001).

A colheita é de fundamental importância no processo produtivo, uma vez que é o momento de colher o fruto dos investimentos realizados. Assim, a mecanização do processo de colheita torna-se ponto de vital importância, tendo em vista a possibilidade de otimização das operações de campo e redução de custos (SILVA, 2004).

A vibração das hastes e o impacto que essas causam, têm-se revelado eficiente método de colheita de diversos produtos agrícolas, tais como: azeitona, citros e nozes (ORTIZ-CAÑAVATE, 1996). As máquinas propostas para a colheita do café, independentemente de seu tamanho, utilizam esse método como princípio de derriça, tendo-se revelado um procedimento eficiente durante a operação de colheita.

Nos primeiros estudos de colheita mecanizada, nos anos de 1975 e 1976, foi projetado um conjunto autopropelido em forma de pórtico, tendo como fonte-motriz um trator agrícola. $\mathrm{O}$ objetivo principal desse conjunto foi o de levantar parâmetros de derriça, freqüência e amplitude de vibração, características da vareta vibratória e transmissão de energia à planta (FAVA, 1990).

O processo de colheita mecanizada, prática que visa à retirada dos frutos da planta com o uso de colhedoras que utilizam a vibração das hastes como princípio de derriça, tem passado por grandes avanços nessas últimas duas décadas, graças ao desenvolvimento tecnológico e a melhorias no processo de colheita (SILVA \& SALVADOR, 1998).

NOGUEIRA et al. (1975) demonstraram que os níveis de danos provocados à estrutura arbórea do cafeeiro são proporcionais ao tempo de aplicação da vibração pela máquina. Esses autores relataram que tempos médios de 10; 20 e acima de 40 segundos podem ocasionar danos em vários níveis ao cafeeiro, podendo ser leves, médios e graves, respectivamente.

Um dos principais danos causados ao cafeeiro pela ação de colhedoras é a desfolha que, na maioria das vezes, é superior à desfolha causada pela colheita manual. Com a desfolha, a planta produzirá menos no ano seguinte, uma vez que utilizará suas reservas para a recomposição da vegetação e, por conseguinte, terá menor frutificação. A ocorrência freqüiente de tal fato proporcionará estressamento da planta e redução de sua longevidade (BÁRTHOLO \& GUIMARÃES, 1997).

Estudos têm demonstrado que a eficiência operacional de colheita chegou a 97\%, sendo possível evitar a operação de repasse (SILVA et al., 2000). O repasse é a operação manual de retirada do restante dos frutos que não foram colhidos mecanicamente.

Estudos analisando a influência da vibração e da velocidade no processo de colheita ainda são pouco freqüentes. Sendo assim, este trabalho teve por objetivo analisar a influência da variação de vibração das hastes e a velocidade de deslocamento no processo de derriça dos grãos com o uso de duas passadas da colhedora de café.

\section{MATERIAL E MÉTODOS}

O experimento foi conduzido na Fazenda Capetinga, localizada no município de Boa Esperança, sul de Minas Gerais, na safra de 2004/2005, em área de $30.000 \mathrm{~m}^{2}$ de lavoura da cultivar Acaiá, com seis anos de idade, plantada no espaçamento de 4,0 m entre linhas e 0,9 m entre plantas, totalizando 2.777 plantas ha $^{-1}$. As coordenadas geográficas são de $21^{\circ} 13$ '20" de 
latitude sul e $45^{\circ} 34^{\prime} 52^{\prime}$ ' longitude oeste, com altitude média de 930 m e declividade média de $8 \%$. O clima da região foi classificado, pelo método de Köeppen, como subtropical com inverno seco (Cwb).

Os ensaios foram realizados utilizando-se do delineamento inteiramente casualizado, com quatro repetições, em parcelas aleatórias, contendo, em média, 40 plantas em linha. Os resultados foram analisados estatisticamente com o auxílio do programa SISVAR (FERREIRA, 2000). Após a análise de variância, os modelos foram escolhidos com base na significância dos coeficientes de regressão, utilizando-se do teste $\mathrm{F}$, a $5 \%$ de probabilidade, e o coeficiente de determinação.

Para a colheita mecanizada do café, foi utilizada a colhedora modelo "KTR", a mais encontrada no sul de Minas. Essa é uma colhedora tracionada que opera acoplada ao sistema hidráulico de três pontos de um trator tipo cafeeiro de $53 \mathrm{~kW}$, cujo funcionamento se faz por meio da TDP, a $9 \mathrm{~Hz}$.

A colhedora, por possuir estrutura tipo pórtico, trabalha montada sobre as plantas e na fileira do cafeeiro, possuindo dois cilindros derriçadores, dotados de hastes vibratórias, que envolvem o cafeeiro lateralmente, derriçando os frutos pelo efeito da vibração das hastes, os quais caem no sistema de recolhimento que, depois de ventilados, são ensacados.

Os ensaios foram realizados com duas passadas da colhedora, sempre na mesma direção de deslocamento, definidos em função do índice de verdes na planta. A primeira passada foi realizada no dia 4-6-2005, com média de 30\% de verde, $30 \%$ de cereja e $40 \%$ de secos na planta, e a segunda passada, 28 dias depois, no dia 2-7-2005, tendo, em média, $10 \%$ de verdes, $40 \%$ de cerejas e $50 \%$ de secos. Em todos os tratamentos, foram utilizadas todas as hastes da colhedora.

Na primeira passada, a velocidade foi fixada em torno de $0,45 \mathrm{~m} \mathrm{~s}^{-1}$, variando-se as vibrações de 10,83; 12,50; 14,17 a $15 \mathrm{~Hz}$, para os tratamentos T1, T2, T3 e T4, respectivamente. Na segunda passada, a vibração foi fixada em $16,67 \mathrm{~Hz}$, variando-se as velocidades de 0,$60 ; 0,72 ; 0,29$ a $0,45 \mathrm{~m} \mathrm{~s}^{-1}$, para os tratamentos $\mathrm{T} 1, \mathrm{~T} 2, \mathrm{~T} 3 \mathrm{e} \mathrm{T} 4$, respectivamente.

A justificativa da fixação da velocidade e variação das vibrações, na primeira passada, e viceversa, na segunda passada, baseia-se no delineamento estatístico utilizado, em custos para execução do experimento e relatos literários a exemplo de SILVA et al. (2002) que desenvolveram trabalho de colheita mecanizada e seletiva do café fixando a velocidade de colheita na primeira passada.

No presente ensaio, o tempo de aplicação da vibração às plantas foram menores que $10 \mathrm{~s}$, servindo também de parâmetro para o aumento da velocidade de colheita, pois esses tempos, certamente, não ocasionariam danos ao cafeeiro, como citam NOGUEIRA et al. (1975).

A quantidade de café colhido em cada parcela foi medida em volume ( planta $\left.^{-1}\right)$. A eficiência de colheita foi determinada dividindo-se o volume de café colhido em cada passada pela carga pendente do cafeeiro, sendo essa uma percentagem da carga total. Para a determinação das perdas de colheita e desfolha, o chão sob a copa de cinco plantas de cada parcela foi forrado. A desfolha foi quantificada em massa de folhas e ramos $\left(\mathrm{kg}_{\text {planta }}{ }^{-1}\right)$, e a quantidade de café caído no chão foi medida em volume ( planta $\left.^{-1}\right)$, sendo considerada perda de colheita.

\section{RESULTADOS E DISCUSSÃO}

A carga pendente média da lavoura foi determinada por amostragem, em 3-6-2005, resultando $11 \mathrm{~L}_{\text {planta }}{ }^{-1}$. Os dados de colheita foram avaliados separadamente, ou seja, a vibração das hastes na primeira passada e a velocidade de deslocamento da colhedora na segunda passada. Isso ocorreu devido ao delineamento estatístico utilizado, pois não tinha como avaliar a interação entre velocidade e vibração na mesma passada.

Com relação à influência da vibração no processo de colheita, pode-se observar, na Figura 1, que, na primeira passada, quanto mais se aumentou a vibração das hastes, maior foi o volume de 
café colhido, isso devido ao efeito da maior ação ou intensidade da vibração das hastes nos cafeeiros. O acréscimo no volume colhido na maior vibração foi de 29,25\% em relação à menor.

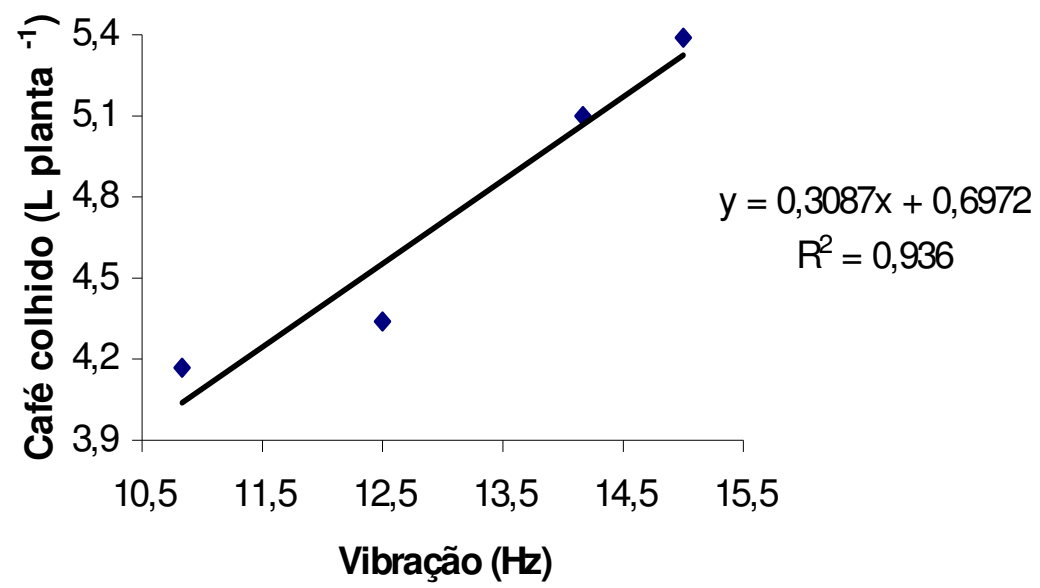

FIGURA 1. Volume de café colhido em função da variação de vibração.

Na Figura 2, demonstra-se a influência da vibração das hastes na eficiência de colheita, na primeira passada, sendo que a eficiência de colheita é a quantidade de café colhido dividida pela carga pendente, ou seja, uma constante. Portanto, apresenta o mesmo comportamento do café colhido. O aumento na eficiência de colheita também pode ser explicado pela maior intensidade de aplicação da vibração das hastes aos cafeeiros. O incremento na eficiência de colheita foi de $29,25 \%$, da menor para a maior vibração.

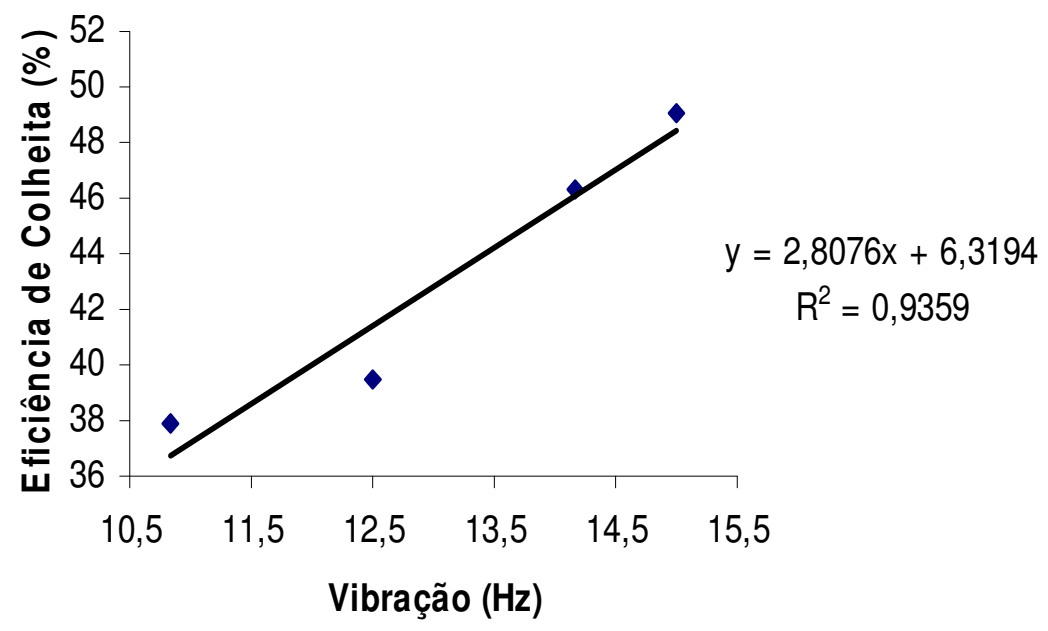

FIGURA 2. Eficiência de colheita em função da variação da vibração.

Com relação ao volume de café caído no chão, observou-se (Figura 3) que, na primeira passada, não houve influência direta da vibração das hastes. Para o modelo em questão, os dados não estão bem ajustados à curva, pois proporcionaram coeficiente de determinação de $73,08 \%$, indicando que somente parte dos dados está ajustada ao modelo.

Analisando-se, na primeira passada da colhedora, a influência da vibração das hastes no processo de desfolha (Figura 4), observou-se que o aumento da desfolha está diretamente ligado ao aumento da intensidade da vibração das hastes. Esse maior desfolhamento pode ser reflexo da maior intensidade de vibração causada pela ação das hastes durante o processo de derriça dos grãos. Na maior vibração, a desfolha foi $31,12 \%$ superior em relação à menor. 


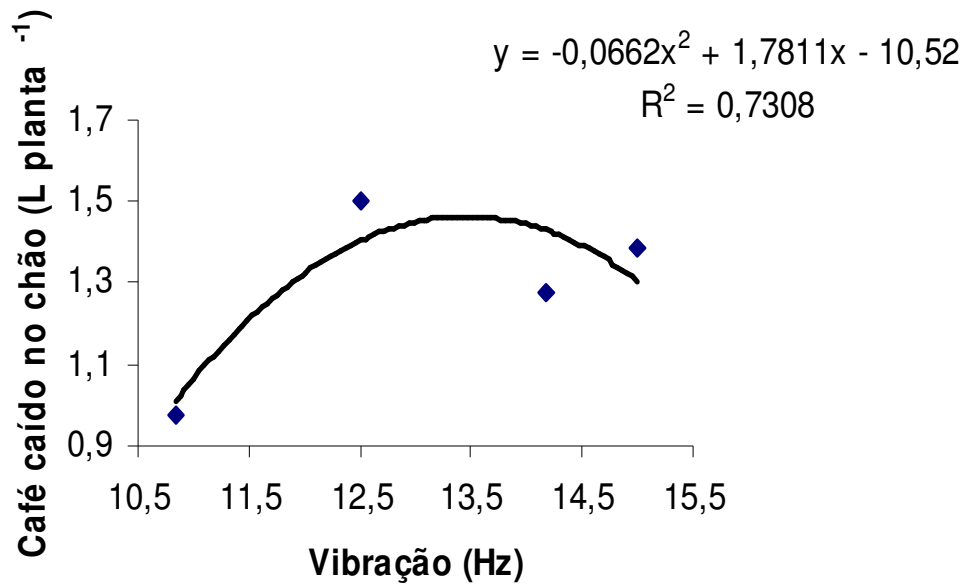

FIGURA 3. Volume de café caído no chão em função da variação da vibração.

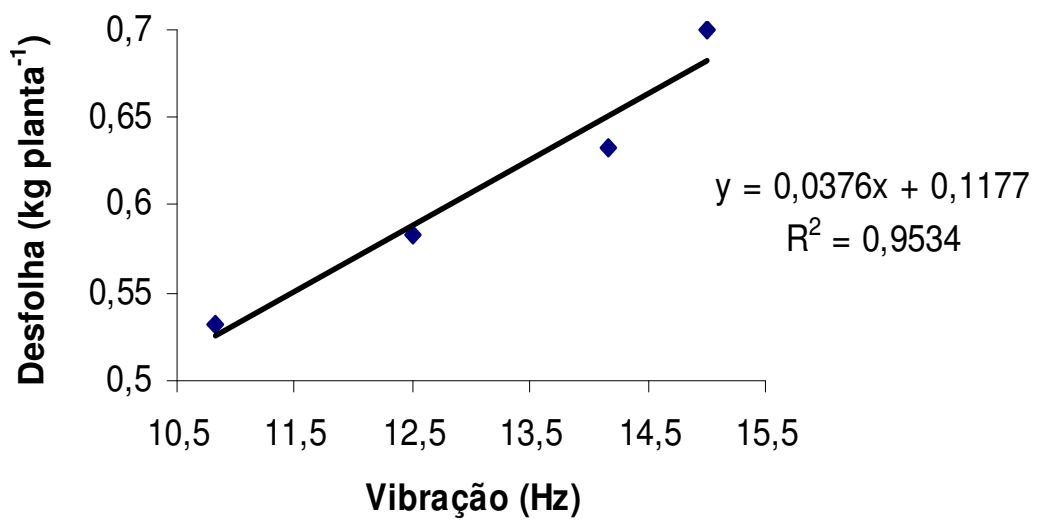

FIGURA 4. Processo de desfolha em função da variação da vibração.

Levando-se em consideração que a eficiência de derriça é a soma do café colhido mais o café caído no chão, dividido pela carga pendente, verificou-se que o aumento da eficiência de derriça na primeira passada está diretamente ligado ao aumento da vibração, pois, analisando-se a Figura 5, nota-se que a eficiência de derriça aumentou com o aumento da intensidade de vibração. $\mathrm{O}$ incremento na eficiência de derriça, na maior vibração, foi de $31,85 \%$ em relação à menor.

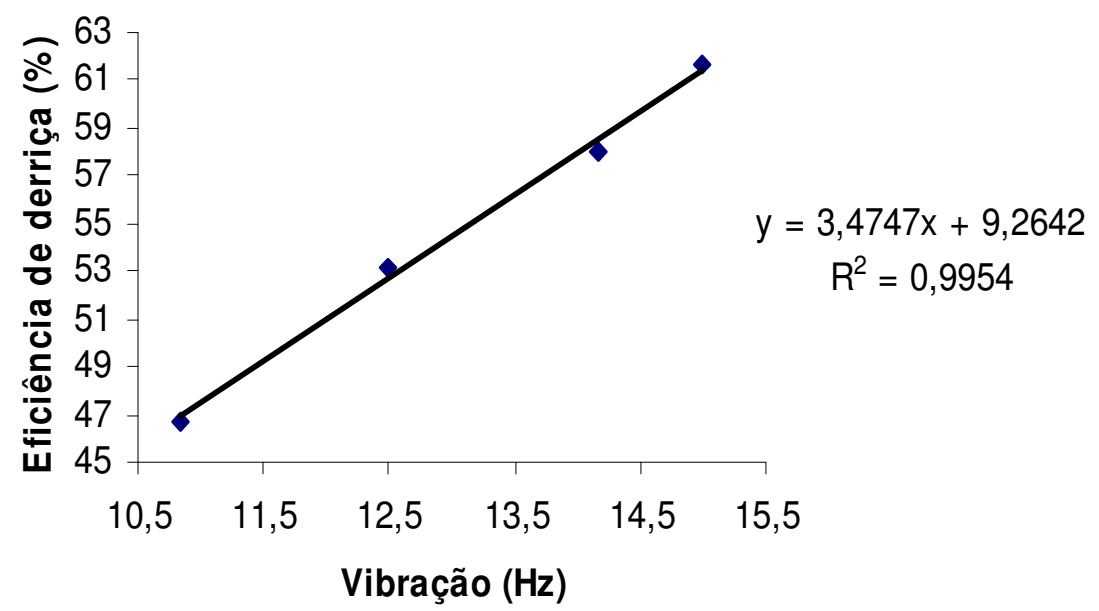

FIGURA 5. Eficiência de derriça em função da variação da vibração.

Analisando-se os resultados da segunda passada, observou-se que o volume de café colhido diminuiu na medida em que se aumentou a velocidade operacional de colheita (Figura 6). A redução do volume colhido da menor para a maior velocidade foi de 14,28\%. O mesmo 
comportamento pôde ser observado em relação à influência da velocidade na eficiência de colheita (Figura 7). Tanto a redução no volume colhido quanto a eficiência de colheita podem ser explicadas pelo menor tempo de exposição do cafeeiro à ação vibratória das hastes e também pela menor quantidade de café presente na planta, uma vez que se trata da segunda passada.

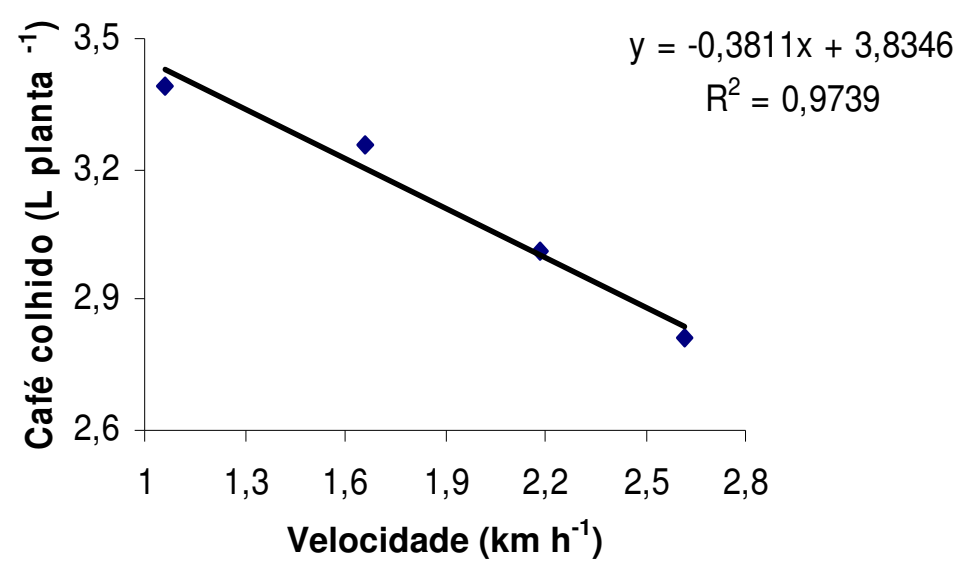

FIGURA 6. Volume de café colhido em função da variação da velocidade.

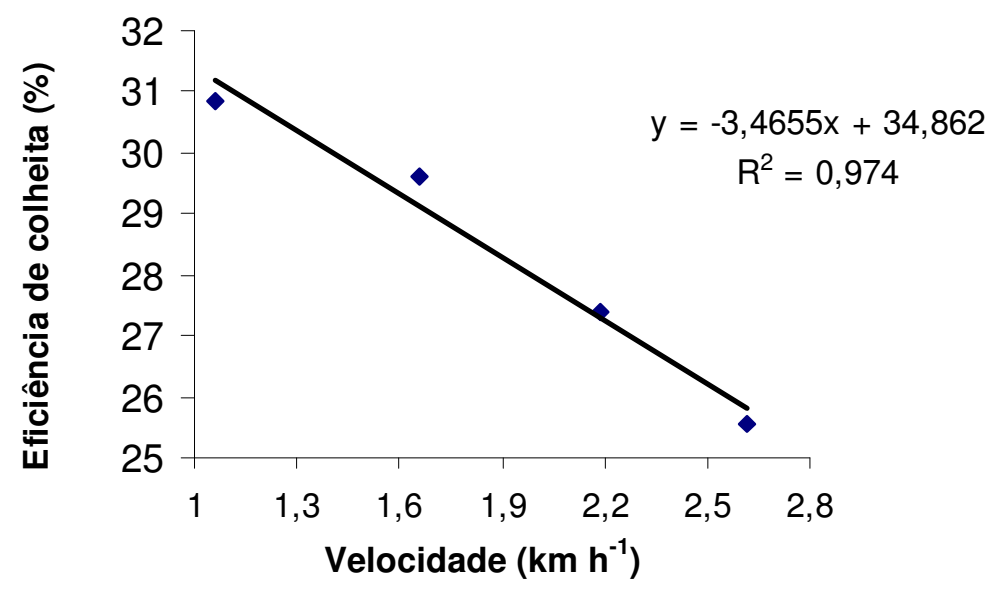

FIGURA 7. Eficiência de colheita em função da variação da velocidade.

Na segunda passada, o volume de café caído no chão sofreu influência direta da variação de velocidade, pois o aumento de velocidade ocasionou maiores volumes (Figura 8). O volume de café caído no chão sofreu incremento de $61,2 \%$ para a maior velocidade em relação à menor.

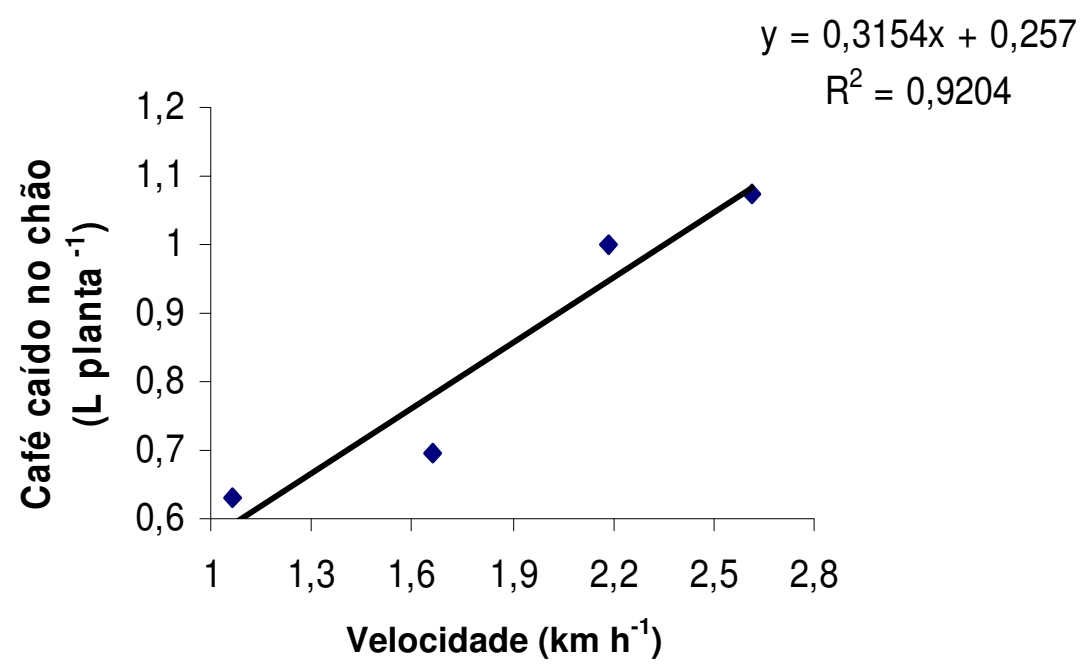

FIGURA 8. Volume de café caído no chão em função da variação da velocidade. 
Porém, pode-se dizer que a desfolha não está diretamente ligada ao aumento de velocidade de colheita na segunda passada, pois a análise de variância dos dados indicou que o modelo não foi significativo, pelo teste $\mathrm{F}$, a $5 \%$ de probabilidade.

Analisando-se os dados de velocidade na segunda passada e sua influência no processo de derriça, observou-se que a velocidade não afetou a eficiência de derriça, pois, pela análise de variância, a $5 \%$ de probabilidade, pelo teste $\mathrm{F}$, os dados não foram significativos. Isso indica que não existem diferenças entre as várias velocidades utilizadas durante a colheita e a variação no processo de derriça dos frutos. A queda na velocidade indicou apenas tendência de aumento na eficiência de derriça.

\section{CONCLUSÕES}

$\mathrm{Na}$ primeira passada, o volume de café colhido e a eficiência de colheita foram, na maior vibração, 29,25\% superiores em relação à menor vibração.

A desfolha na primeira passada foi $31,12 \%$ superior na maior vibração, e a eficiência de derriça foi superior em $31,85 \%$ também na maior vibração.

Na segunda passada, na maior velocidade operacional, o volume de café caído no chão variou $61,2 \%$ em relação à menor velocidade, e a redução no volume colhido e na eficiência de colheita variou em $14,28 \%$, da menor para a maior velocidade operacional.

\section{AGRADECIMENTOS}

À empresa Jacto Máquinas Agrícolas S.A., pelo suporte técnico, e à Fazenda Capetinga, pela concessão da área experimental.

\section{REFERÊNCIAS}

BÁRTHOLO, G.F.; GUIMARÃES, P.T.G. Cuidados na colheita e preparo do café. Informe Agropecuário, Belo Horizonte, v.18, n.187, p.33-42, 1997.

FAVA, J.F.M. O desenvolvimento da colhedora de café. In. CICLOS DE ESTUDOS SOBRE MECANIZAÇÃO AGRÍCOLA, 4., 1990, Campinas. Anais... Campinas: Fundação CARGILL, 1990. p.234-46.

FERREIRA, D.F. Análises estatísticas por meio do SISVAR (Sistema para Análise de Variância) para Windows® versão 4.0. In: REUNIÃO ANUAL DA REGIÃO BRASILEIRA DA SOCIEDADE INTERNACIONAL DE BIOMETRIA, 45., 2000, São Carlos. Resumos... São Carlos: UFSCar, 2000. p.255-8.

FILGUEIRAS, W. H. Modelagem da planta de café por elementos finitos para estudos de colheita por vibração. 2001. 81 f. Dissertação (Mestrado em Mecanização Agrícola) - Universidade Federal de Viçosa, Viçosa - MG, 2001.

IBC. INSTITUTO BRASILEIRO DO CAFÉ. Podas. In: . Cultura do café no Brasil. Manual de recomendações. Rio de Janeiro: IBC/GERCA, 1974. p.207-26.

NOGUEIRA, V.S.; HASHIZUME, H.; SILVA, J.B.S.; CARNEIRO FILHO, F.; MATIELLO, J.B. Estudos de colheita de café com derriçadeiras vibratórias portáteis. In. CONGRESSO BRASILEIRO DE PESQUISAS CAFEEIRAS, 3., 1975, Curitiba. Anais... Rio de Janeiro: IBC, 1975. p.239-42.

ORTIZ-CAÑAVATE, J. Cosecha mecanizada de fruta por el método de vibraciones forzadas. Revista Ciencias Tecnicas Agropecuarias, Habana, v.6, n.1, p.76-84, 1996.

SILVA, F.M. Colheita mecanizada e seletiva do café - cafeicultura empresarial: produtividade e qualidade. Lavras: UFLA/FAEPE, 2004. 75 p. 
SILVA, F.M.; OLIVEIRA, E.; SALVADOR, N.; TOURINO, E.S. Avaliação da colheita mecanizada e seletiva do café. In. CONGRESSO BRASILEIRO DE PESQUISAS CAFEEIRAS, 28., 2002, Caxambu. Anais... Rio de Janeiro: MAPA/PROCAFÉ, 2002. p.150-2.

SILVA, F.M.; RODRIGUES, R.F.; SALVADOR, N.; TOURINO, E.S.; SILVA, S.S.S. Custo da colheita mecanizada de café com colhedoras automotrizes no Sul de Minas. Engenharia na Agricultura, Viçosa, v.8, n.1, p.54-60, 2000.

SILVA, F.M.; SALVADOR, N. Mecanização da lavoura cafeeira: colheita. Lavras: UFLA/DEG, 1998. 55 p. Boletim técnico 